\title{
WHITE PAINTING PIGMENT AS A LOW-COST LIGHT SCATTERING MATERIAL FOR BILAYER PHOTOELECTRODES OF DYE-SENSITIZED SOLAR CELLS
}

\section{P. Joshi}

Journal of Nepal Physical Society

Volume 5, Issue 1, October 2019

ISSN: $2392-473 X$

Editors:

Dr. Vinaya Kumar Jha

Dr. Binod Adhikari

Dr. Kapil Adhikari

JNPS, 5 (1), 1-5 (2019)
JiPS

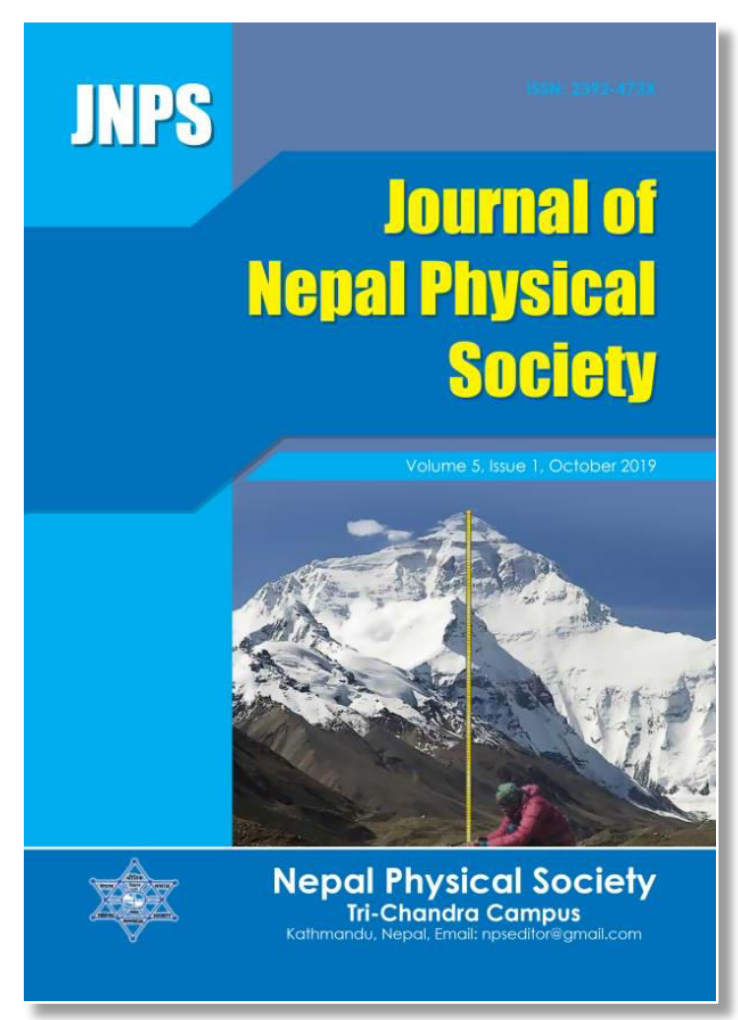

Published by:

Nepal Physical Society

P.O. Box: 2934

Tri-Chandra Campus

Kathmandu, Nepal

Email: npseditor@gmail.com 


\title{
WHITE PAINTING PIGMENT AS A LOW-COST LIGHT SCATTERING MATERIAL FOR BILAYER PHOTOELECTRODES OF DYE-SENSITIZED SOLAR CELLS
}

\author{
P. Joshi \\ Physics Department, Bhaktapur Multiple Campus, Tribhuvan University, Bhaktapur, Nepal \\ Corresponding Email: joship7@gmail.com
}

\begin{abstract}
White pigment (DuPont R902+) has been used as a light scattering material in the preparation of bilayer photoelectrodes of dye-sensitized solar cells (DSCs). The X-ray diffraction (XRD) pattern of the white pigment revealed that the material consists of rutile phase of titanium dioxide. The light scattering layer prepared from the white pigment was coated onto the main-layer of the photoelectrodes of DSCs. The solar cells with and without light scattering layer were tested in the simulated light of $100 \mathrm{~mW} / \mathrm{cm}^{2}$. The DSCs with the light scattering layer generated more current density than the DSCs without scattering layer and the overall light to electric power conversion efficiency of DSCs with the light scattering layer was $~ 4.00 \%$ compared with $3.25 \%$ efficiency of the DSCs without the scattering layer.
\end{abstract}

Keywords: Dye-sensitized solar cell, Light scattering layer, Photoelectrode, Rutile titanium dioxide, Transmittance, White pigment (R902+)

\section{INTRODUCTION}

Dye-sensitized solar cells (DSCs) are considered as cost-effective devices for the generation of electricity from sunlight compared with silicon wafer based solar cells [1]. Fig. 1 is a schematic diagram of a typical DSC. Basically, a DSC consists of three components-photoelectrode, liquid electrolyte and counter electrode (CE); the electrolyte is sandwiched between two electrodes [2-4]. The photoelectrode is a transparent conducting oxide (TCO)-glass substrate like fluorine doped tin oxide (FTO)-glass substrate. Generally, the TCO is coated with a thin film of nanocrystalline titanium dioxide $\left(\mathrm{TiO}_{2}\right)$, which is sensitized with a monolayer of dye-molecules [5-6]. When the dye-molecules are exposed to sunlight, electrons are ejected from the dye molecules. The photoelectrons diffuse in the $\mathrm{TiO}_{2}$ film and they arrive at the conducting part of the photoelectrode. The photo-generated electrons flow to the $\mathrm{CE}$ through a load connected across the two electrodes $[3,6]$. The CE is also an FTO-glass substrate with a thin film of platinum on its conducting side $[3,7]$. The liquid electrolyte contains iodide ions $\left(\mathrm{I}^{-}\right)$and tri-iodide ions $\left(\mathrm{I}_{3}{ }^{-}\right)$. The iodide ions $\left(\mathrm{I}^{-}\right)$regenerate the oxidized dye molecules by donating electrons and the iodide ions turn into tri-iodide ions. On the other hand, the iodide ions are regenerated after the tri-iodide ions gain electrons from the $\mathrm{CE}[3,6]$.

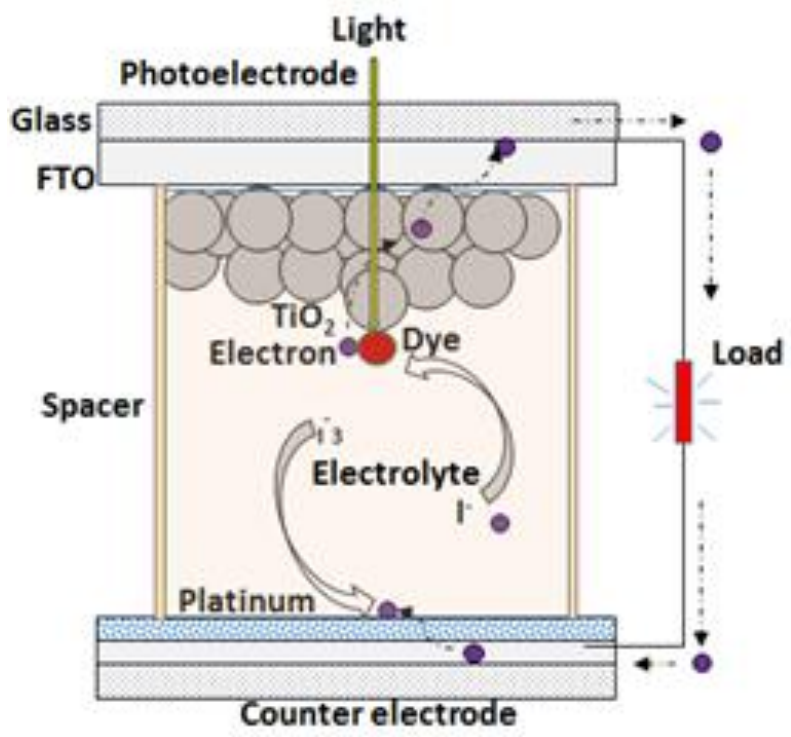

Fig. 1: A schematic of dye-sensitized solar cell. Modified from ref. [2].

Since O'Regan and Gratzel reported highly efficient and low-cost DSCs in 1991, these solar cells have been remained as attractive photovoltaic 
devices among researchers [8] and overall light to electricity conversion efficiency of DSCs has reached $\sim 13 \%$ [9]. Furthermore, the researchers are making efforts to increase the power conversion efficiency and reduce the fabrication cost of DSCs by optimizing their components. Photoelectrodes are considered as a prominent part of DSCs as it can greatly influence both the power conversion efficiency [8] and the fabrication cost of the photovoltaic device [4]. Various types of bilayer photoelectrodes (comprising a layer of mesoporous nanocrystalline $\mathrm{TiO}_{2}$ film as the main-layer and a layer of submicron to micron sized $\mathrm{TiO}_{2}$ film as the light scattering layer) have been recommended by previous researchers to enhance light to electric power conversion efficiency of the DSCs and reduce the fabrication cost of the devices $[4,8,10]$. In this research, low-cost white pigment (R902+, DuPont) has been used in the preparation of an efficient light scattering layer in DSCs. The composition of the white pigment was analyzed by means of X-ray diffraction (XRD) and the surface morphology of the scattering layer was investigated by means of atomic force microscope. Also, the light scattering ability of the scattering layer was evaluated by comparing transmittance of the scattering layer with that of the main-layer. Similarly, photovoltaic performances of DSCs with and without the scattering layer were also investigated.

\section{EXPERIMENTAL METHOD}

The chemicals and materials required for fabrication of the DSCs were obtained as described below. Fluorine-doped tin oxide (FTO)-glass substrates (sheet resistance of $\sim 8 \Omega / \square$ ) were purchased from Hartford Glass Co., USA. The $\mathrm{TiO}_{2}$ (Ti-Nanoxide HT/SP) paste required for preparation of the main- layer of photoelectrode, Ruthenium based sensitizer (Ruthenizer 535-bisTBA also called N-719), liquid electrolyte (Iodolyte HI-30) and platinum precursor (Platisol T) were purchased from Solaronix, Switzerland. Rutile $\mathrm{TiO}_{2}$ white pigment (Du-pont, R902+, Pure-Ti Powder) were obtained from a painting industry in Bhaktapur. Similarly, terpineol and ethylcellulose were purchased from the agent of Sigma Aldrich Company in Kathmandu.

The procedures for the fabrication of DSCs were as described below. First of all, three types of photoelectrode were prepared. One type of the photoelectrodes have only main-layer prepared from nanocrystalline $\mathrm{TiO}_{2}$ and another type of the photoelectrodes have bilayer structure comprising a main-layer and a scattering layer; the scattering layer was coated onto the main-layer. The third type of photoanodes has scattering layer only.

The main-layer of photoelectrode was prepared by doctorblading a thin film of nanocrystalline $\mathrm{TiO}_{2}$ (Ti-Nanoxide HT/SP) paste onto cleaned FTO-glass substrates. The FTO-glass substrates with the dotorbladed film were sintered first at $100^{\circ} \mathrm{C}$ for $\sim 30$ minutes, then at $\sim 450^{\circ} \mathrm{C}$ for $\sim 45$ minutes. The photoelectrodes with bilayer structure were prepared by doctorblading thin film of light scattering layer (the paste of the white pigment with terpineol and ethyl cellulose) onto the main-layer and then sintering the film as described above. Similarly, the photoelectrodes with scattering layer only (without main-layer) were prepared by doctorblading the paste of the white pigment directly onto the FTO and sintering the FTO-glass substrates at a similar temperature as described above. In order to sensitize the sintered $\mathrm{TiO}_{2}$ films, the $\mathrm{TiO}_{2}$ films were allowed to cool at $\sim 80{ }^{\circ} \mathrm{C}$ in air, and then they were immersed into the $0.5 \mathrm{mM}$ solution of N-719 dyes in anhydrous ethanol for two days. The counter electrodes of the DSCs were prepared by coating the solution of Platisol $\mathrm{T}$ onto clean FTOs, then sintering the FTOs with the platinum precursor at $450^{\circ} \mathrm{C}$ for $\sim 30$ minutes.

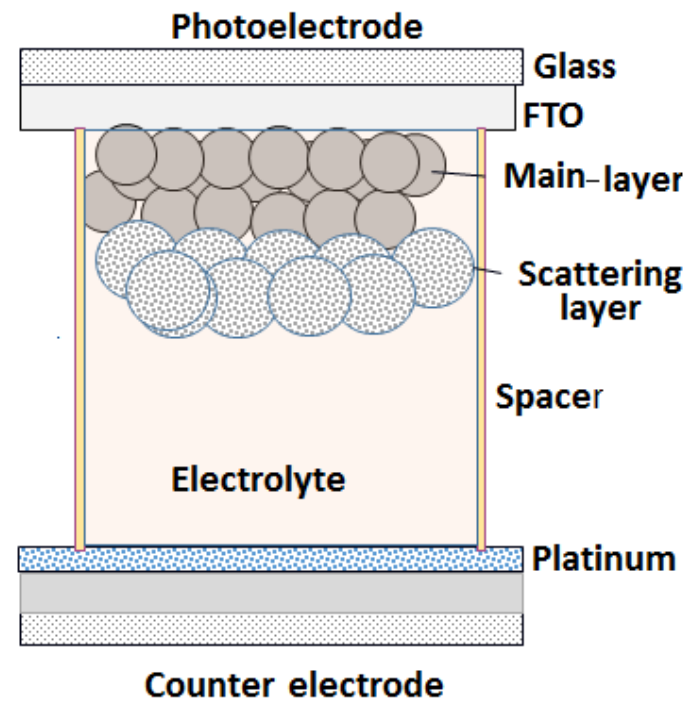

Fig. 2: Schematic diagram of a DSC with bilayer structure of photoelectrode.

The photoelectrodes and counter electrodes were assembled by using parafilm (as sealant and spacer). Finally, the liquid electrolyte (Iodolyte HI30) containing iodide/tri-iodide ions was injected 
into the space between the two electrodes. The DSCs with the main-layer (single layer), with the bilayer structure and with scattering layer (single layer) were named DM, DMS and DS, respectively. The active area of all of the DSCs was $\sim 0.126 \mathrm{~cm}^{2}$. The photovoltaic characterization of the DSCs was carried out in simulated light of $\sim 100 \mathrm{~mW} / \mathrm{cm}^{2}$ from Abet SunLite Solar Simulator 11002 at Kathmandu University, Nepal. The cells were tested with masking to avoid over-estimation of light to electricity conversion efficiency [11].

The structural analysis of the white pigment was carried out by means of the X-ray diffractometer available at Nepal Academy of Science and Technology (NAST). Similarly, the surface morphology of main-layer and light scattering layer was explored with an atomic force microscope (Multimode SPM, Veeco Metrology Group) at physics department in Brooklyn College, the Graduate Centre, the City University of New York, USA. Similarly, the transmittance of the bare FTO, FTO with main-layer and FTO with bilayer structure (main-layer coated with light scattering layer) was studied at the same institution.

\section{RESULTS AND DISCUSSION}

Fig. 3 is the X-ray diffraction (XRD) pattern of the white pigment (DuPont R902+) used for the preparation of the light scattering layer. The diffraction peaks indicate that the white pigment consists of rutile phase of $\mathrm{TiO}_{2}$ [12].

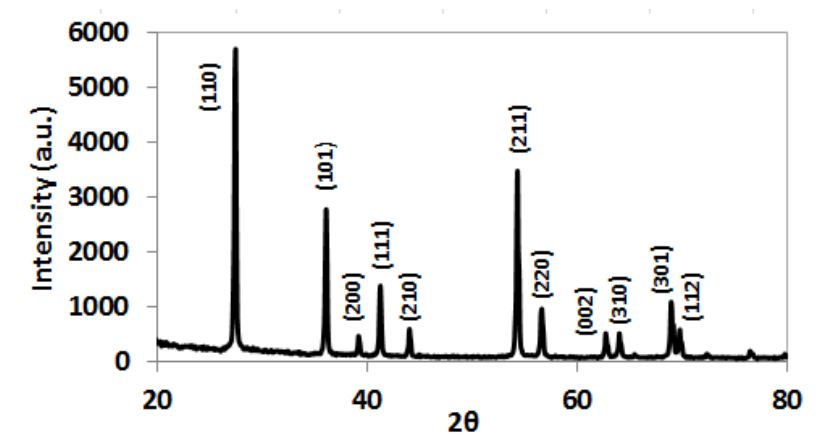

Fig. 3: X-ray diffraction of white pigment (DuPont R902+).

Fig. 4 is the AFM images of light scattering layer and main-layer. The grains seen in the scattering layer (Fig. 4a) are much larger than those seen in main-layer (Fig. 4b). Moreover, the surface morphology of the scattering layer seems smoother than that of the main-layer. This indicates that the surface roughness of the scattering layer is much smaller than that of the main-layer.
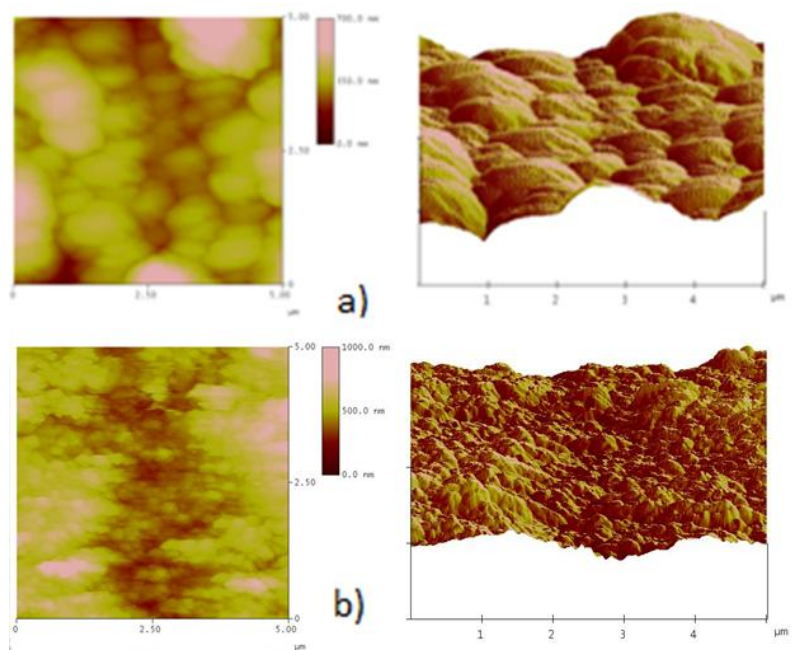

Fig. 4: AFM images of a) scattering layer and b) main-layer.

Fig. 5 shows the transmittance of FTO, main-layer and scattering layer without dye molecules. The transmittance of the scattering layer is significantly smaller compared with that of the main-layer. This implies that the reflectance of light scattering layer is significantly high.

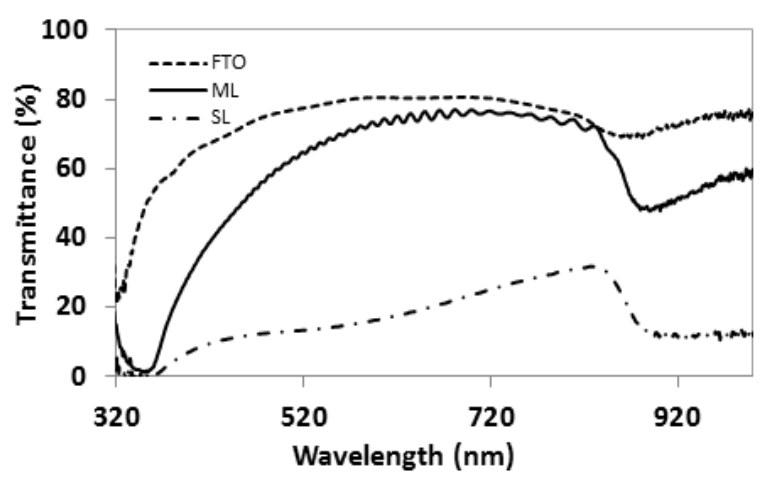

Fig. 5: Transmittance of FTO, main layer and scattering layer without dye molecules.

Fig. 6 shows the current density versus voltage (JV) curves of DS, DM, and DSM. Table 1 enlists the photovoltaic parameters of the devices. The overall power conversion efficiency ( $\eta$ ) of DS only was $\sim 0.02 \%$. Similarly, its $\mathrm{J}_{\mathrm{sc}}$ was only $\sim 0.15 \mathrm{~mA} / \mathrm{cm}^{2}$. This indicates that the scattering layer does not generate a significant amount of photo-current. This (small photo-current) may be due to the attachment of negligibly small amount of dye on the light scattering layer. 

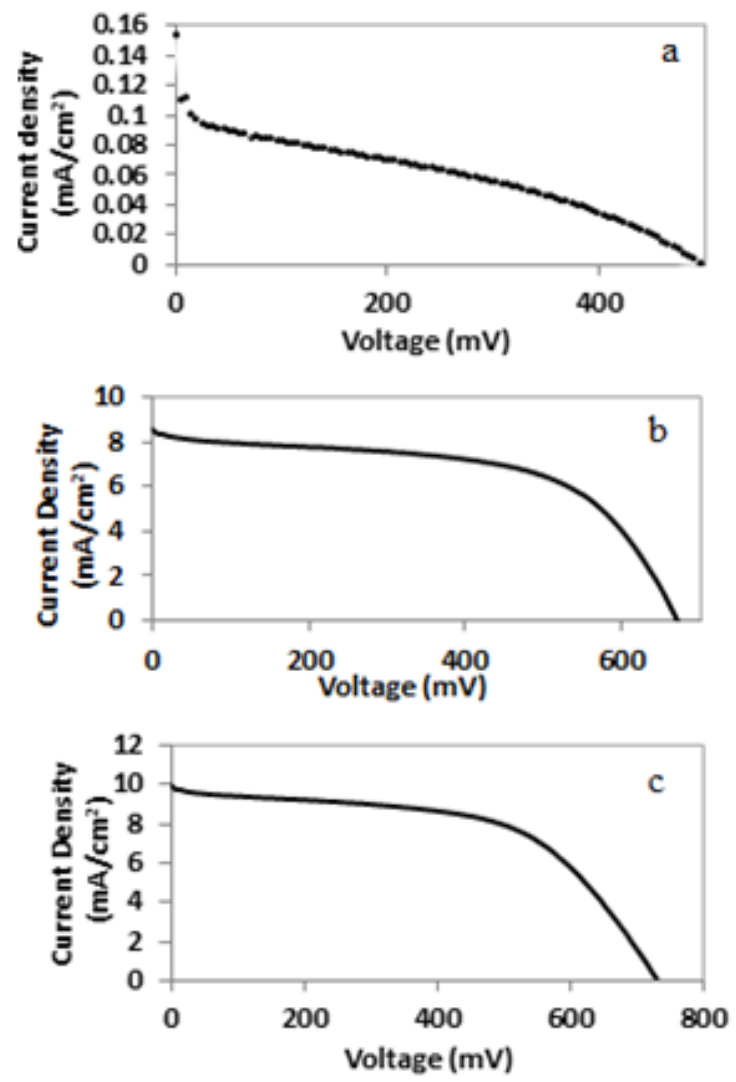

Fig. 6: $J$-V curves of DS, DM, and DSM.

Similarly, the overall light to electric power conversion efficiency of DM and DMS were 3.25 $\%$ and $4.00 \%$, respectively. The enhanced power conversion efficiency of DMS was due to the increase in current density. The short circuit current density $\left(\mathrm{J}_{\mathrm{sc}}\right)$ of DM and DMS were $8.57 \mathrm{~mA} / \mathrm{cm}^{2}$ and $9.96 \mathrm{~mA} / \mathrm{cm}^{2}$, respectively. The low current density of DM implies that the main-layer transmits some of the incident light photons without generating photo-electrons. On the other hand, the high current density of DMS indicates that the scattering layer reflects light photons transmitted through the main-layer. This fact is supported by the significantly low transmittance of the scattering layer as seen in Fig. 5.

Table 1: Photovoltaic parameters of DSCs.

\begin{tabular}{|l|l|c|l|l|}
\hline DSCs & $\begin{array}{c}|c| \\
\mathbf{J}_{\text {sc }} \\
\left(\mathbf{m A} / \mathbf{c m}^{\mathbf{2}}\right)\end{array}$ & $\begin{array}{c}\mathbf{V}_{\text {oc }} \\
(\mathbf{V})\end{array}$ & \multicolumn{1}{|c|}{} & $\begin{array}{c}\mathbf{n} \\
(\boldsymbol{\%})\end{array}$ \\
\hline DS & 0.15 & 0.500 & 0.220 & 0.02 \\
\hline DM & 8.57 & 0.672 & 0.563 & 3.25 \\
\hline DMS & 9.96 & 0.731 & 0.549 & 4.00 \\
\hline
\end{tabular}

\section{CONCLUSIONS}

Low-cost white painting pigment primarily used in painting industries has been employed as a light scattering material in DSCs. The XRD of the white pigment reveals that the pigment comprises mainly $\mathrm{TiO}_{2}$ in rutile phase. The scattering layer exhibited a high reflectance (or low transmittance) for incident light photons. The overall power conversion efficiency of DSCs was improved after the addition of the scattering layer onto the mainlayer of photoelectrodes and the employment of the scattering layer in DSCs may contribute to reduce the cost of the electricity generated from the DSCs.

\section{ACKNOWLEDGMENTS}

The author acknowledges the contribution from following personnel and institutions: Bhaktapur Multiple Campus (BMC), Tribhuvan University (T.U.), Nepal, Associate Prof. Dr. Mim Lal Nakarmi and Mr. Nikesh Maharjan (Brooklyn College, the Graduate Centre, the City University of New York, USA), Dr. Suresh Dhungel and Mr. Madhav Kafle from Nepal Academy of Science and Technology (NAST), Dr. Bhim Kafle (Kathmandu University, Nepal) and Associate Prof. Sudarshana Shakya, Assistant Campus Chief (BMC).

\section{REFERENCES}

[1] O'Regan, B. and Gratzel, M. A Low-Cost, HighEfficiency Solar-Cell Based on Dye-Sensitized Colloidal $\mathrm{TiO}_{2}$ Films. Nature, 353, 737-740 (1991).

[2] Gratzel, M. Perspectives for Dye-sensitized Nanocrystalline Solar Cells. Prog. Photovolt. Res. Appl. 8, 171-185 (2000).

[3] Joshi, P. Novel Counter Electrodes of Dye Sensitized Solar Cells Based on Activated Carbon Prepared from Wood of Choerospondias axillaris Seed-stones and Alnus nepalensis Plant. International Journal of Engineering and Advanced Research Technology (IJEART), 3, 8-11 (2017).

[4] Hore, S., Vetter, C., Kern, R., Smit, H. and Hinscha, A. Influence of scattering layers on efficiency of dye-sensitized solar cells. Solar Energy Materials and Solar Cells, 90, 1176-1188 (2006).

[5] Joshi, P., Xie, Y., Ropp, M., Galipeau, D., Bailey, S. and Qiao, Q. Dye-sensitized Solar Cells Based on Low Cost Nanoscale Carbon/TiO 2 Composite Counter Electrode. Energy Environ. Sci., 2, 426-429 (2009).

[6] Karki, S., Shakya, S., Rajbhandari (Nyachhyon), A., Shrestha, D. and Joshi, P. Low- 
cost Dye-sensitized Solar Cells with Novel Counter Electrodes based on Activated Carbon of Rhododendron Arboreum Plant Wood. International Journal of Scientific Engineering and Applied Science (IJSEAS), 3, 134-138 (2017).

[7] Gratzel, M. Solar Energy Conversion by DyeSensitized Photovoltaic Cells. Inorg. Chem., 44, 6841-6851 (2005).

[8] Koo, H., Park, J., Yoo, B., Yoo, K., Kim, K. and Park, M. Size-dependent scattering efficiency in dye-sensitized solar cell, Inorganica Chimica Acta, 361, 677-683 (2008).

[9] Mathew, S., Yella, A., Gao, P., Humphry-Baker, R., Curchod, B. F. E., Ashari-Astani, N., Tavernelli, I., Rothlisberger, U., Nazeeruddin, Md. K. and Gratzel, M. Dye-sensitized solar cells with $13 \%$ efficiency achieved through the molecular engineering of porphyrin sensitizers, Nat Chem., 6, 242-247 (2014).

[10] Ferber, J. and Luther, J. Computer simulations of light scattering and absorption in dye-sensitized solar cells. Sol. Energy Mater. and Sol. Cells, 54, 265-275 (1998).

[11] Ito, S., Nazeeruddin, M., Liska, P., Comte, P., Charvet, R., Pechy, P., Jirousek, M., Kay, A., M. Zakeeruddin, S. and Gratzel, M. Photovoltaic Characterization of Dye-Sensitized Solar Cells: Effect of Device Masking on Conversion Efficiency. Prog. Photovolt: Res. Appl. 14, 589601 (2006).

[12] Thamaphat, K., Limsuwan, P. and Ngotawornchai, B. Phase Characterization of $\mathrm{TiO}_{2}$ Powder by XRD and TEM. Kasetsart J. (Nat. Sci.), 42, 42357 - 361 (2008). 